\title{
Effect of Hot-band Annealing Condition on Secondary Recrystallization in Grain-oriented 2.3\%Si-1.7\%Mn Steel
}

\author{
Tomoki FUKAGAWA and Hiroyoshi YASHIKII
}

Electronics Engineering Laboratories, Sumitomo Metal Industries, Ltd., Fuso-cho Amagasaki, Hyogo, 660-0891 Japan. 1) Wakayama Steel Works, Sumitomo Metal Industries, Ltd., Minato, Wakayama, 640-8555 Japan.

(Received on October 12, 1999; accepted in final form on December 16, 1999)

\begin{abstract}
The effect of hot-band annealing temperature on secondary recrystallization was investigated using the hot-rolled steel sheets containing ultra-low C-2.3\% Si-1.7\% Mn-0.01\%sol.Al of $2.3 \mathrm{~mm}$ thickness. The followings were found.

When the hot-bands doesn't recrystallize after the hot-band annealing at 600 and $625^{\circ} \mathrm{C}$, secondary recrystallization of the $\{110\}\langle 001\rangle$ orientation mixed with the $\{211\}\langle 011\rangle$ orientation forms. This is because the $\{110\}\langle 001\rangle$ orientation density is too weak in the primary recrystallization texture. That also occurs when the inhibitor is too weak in the secondary recrystallization stage. Fully recrystallized hot-band after annealing at $700^{\circ} \mathrm{C}$ leads to no secondary recrystallization. The reason is that very coarse primary recrystallized grains at the center layer prevent secondary recrystallization. Secondary recrystallization of the $\{110\}\langle 001\rangle$ orientation evolves completely when only near surface layer but not the center layer of the hot-band recrystallize after the hot-band annealing at 650 and $675^{\circ} \mathrm{C}$. The reason is because amount of $\{110\}\langle 001\rangle$ component in the primary texture, the inhibitor intensity and the primary matrix grain size structure are satisfied.
\end{abstract}

KEY WORDS: electrical steel; recrystallization; Goss, texture.

\section{Introduction}

Recently a new process of grain-oriented electrical steel using ultra-low $\mathrm{C}$-high $\mathrm{Mn}$ steel has been proposed. ${ }^{1)}$ The chemical composition has the following characteristic points.

(1) $\mathrm{Mn}$ is partly substituted for $\mathrm{Si}$ in ultra-low carbon steel in order to cause $\gamma / \alpha$ transformation and in order to compensate the steel for the specific resistivity.

(2) A very few amount of $\mathrm{Al}$ (about $0.01 \%$ ) is added in order to form (Al, Si, Mn) nitrides which act as inhibitors during the secondary recrystallization annealing.

The new production process using above composition is composed of hot-rolling, hot-band annealing, cold rolling, preannealing, secondary recrystallization annealing and purification annealing. These steps are the same as the onestage cold-rolling process $^{2)}$ for grain-oriented electrical steel. However, the new process provides lower production cost compared with the conventional process. This is because the slab soaking temperature and the subsequent annealing temperature are lower. For example, in the conventional process, the slab soaking temperature is $1350^{\circ} \mathrm{C}$ for the solution treatment of $\mathrm{MnS}$ and the final annealing temperature for purification is $1200^{\circ} \mathrm{C}$. But in the new process, the slab soaking temperature is not higher than $1200^{\circ} \mathrm{C}$ and the final annealing temperature is not higher than $1000^{\circ} \mathrm{C}$, respectively.

In the present study, effect of the hot-band annealing temperature on the primary recrystallization texture and furthermore the secondary recrystallization behavior in the new steel has been investigated.

\section{Experimental Procedures}

Hot-rolled steel sheets containing $0.0023 \% \mathrm{C}-2.35 \% \mathrm{Si}-$ $1.68 \% \mathrm{Mn}-0.012 \% \mathrm{P}-0.005 \% \mathrm{~S}-0.0124 \%$ sol.Al-0.0042\%N of $2.3 \mathrm{~mm}$ thick were used as specimen, as given in Table 1. Schematic diagram of experimental procedure is given in Fig. 1.

Their hot-bands were heated to the temperature from 600 to $700^{\circ} \mathrm{C}$ at a rate of $40^{\circ} \mathrm{C} / \mathrm{h}$, held for $1 \mathrm{~h}$ in $\mathrm{Ar}$ and cooled to the room temperature at the rate of $40^{\circ} \mathrm{C} / \mathrm{h}$. Next they were cold-rolled to $0.35 \mathrm{~mm}$ in thickness. Then specimens of $100 \mathrm{~mm}$ wide and $280 \mathrm{~mm}$ long were cut from the coldrolled sheets and preannealed at $880^{\circ} \mathrm{C}$ for $1 \mathrm{~min}$ in salt bath for primary recrystallization. Furthermore the specimens were heated to $875^{\circ} \mathrm{C}$ at a rate of $40^{\circ} \mathrm{C} / \mathrm{h}$ and held for $24 \mathrm{~h}$ in atmospheres of $15 \% \mathrm{~N}_{2}+85 \% \mathrm{H}_{2}$ or $5 \% \mathrm{~N}_{2}+95 \% \mathrm{H}_{2}$ for secondary recrystallization.

The textures and the microstructures were investigated after the hot-band annealing and the primary recrystallization annealing. Optical microstructures of the cross section along the rolling direction of their specimens were ob-

Table 1. Chemical comosition of a test steel. (mass\%)

\begin{tabular}{cccccccc}
\hline $\mathrm{C}$ & $\mathrm{Si}$ & $\mathrm{Mn}$ & $\mathrm{P}$ & $\mathrm{S}$ & $\mathrm{Sol} . \mathrm{Al}$ & $\mathrm{N}$ & 0 \\
\hline 0.0023 & 2.35 & 1.68 & 0.012 & 0.005 & 0.0124 & 0.0042 & 0.0033 \\
\hline
\end{tabular}


served.

The $\langle 110\rangle,\langle 211\rangle$ and $\langle 111\rangle$ axis density parallel to the normal direction was measured at the $1 / 10$ and $1 / 2$ thickness from the sheet surface of the primary recrystallized specimens. In addition, the $\{100\}$ pole figures were also measured at the same position of the hot-band annealed specimens and the primary recrystallized specimens. Three dimensional orientation distribution of texture after primary recrystallization was obtained as following; the $\{110\} \mathrm{im}-$ perfect pole figures were measured at the position of $1 / 10$ and $1 / 2$ thickness from the sheet surface by X-ray diffraction method and converted by the vector method. ${ }^{3)}$ The macrostructures were observed after the secondary recrystallization annealing. The orientations of the secondary recrystallized grains were investigated by the back reflection Laue diffraction method.

The magnetic properties in the rolling direction of the specimens after the final annealing were measured using a single sheet tester.

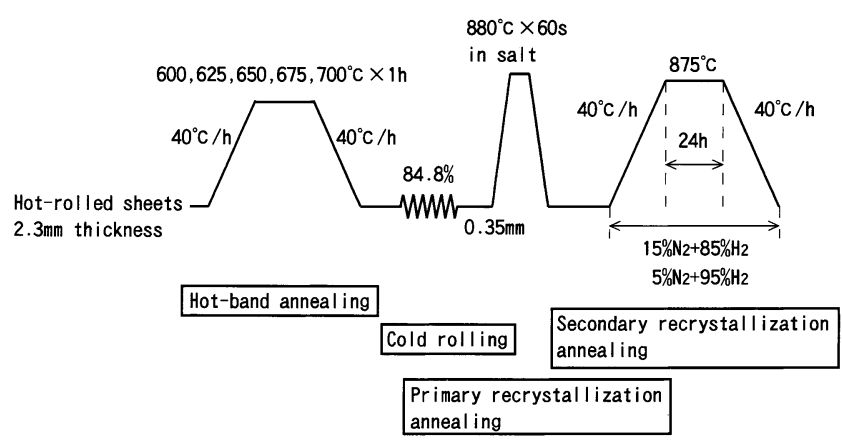

Fig. 1. Schematic diagram of the experimental procedure.

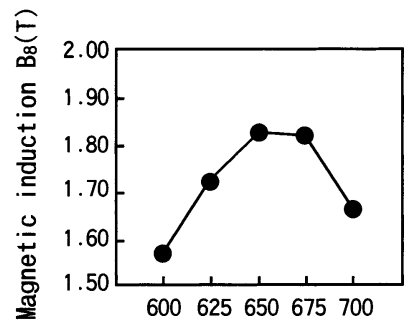

Hot-band annealing temperature $\left({ }^{\circ} \mathrm{C}\right)$

Fig. 2. Effect of hot-band annealing temperature on magnetic property after final annealing.

\section{Experimental Results}

\subsection{Magnetic Properties and Macrostructures after Secondary Recrystallization Annealing}

Effect of the hot-band annealing temperature on the magnetic properties and the macrostructures after the final annealing are shown in Figs. 2 and 3 respectively. The magnetic induction $B_{8}$ corresponding to the sharpness of $\{110\}\langle 001\rangle$ texture is low and equiaxed secondary grains mixed with many elongated secondary recrystallized grains form when the hot-bands are annealed at $600^{\circ} \mathrm{C}$ and $625^{\circ} \mathrm{C}$. On the other hand, the magnetic induction $B_{8}$ indicates the highest value and large equiaxed secondary grains are evolved when the hot-bands are annealed at $650^{\circ} \mathrm{C}$ and $675^{\circ} \mathrm{C}$. Hot-band annealing at $700^{\circ} \mathrm{C}$ results in low $B_{8}$ value and no secondary recrystallization. The $\{100\}$ pole figures of the secondary recrystallized grains are shown in Fig. 4. The elongated secondary recrystallized grains have the $\{211\}\langle 011\rangle$ texture obviously when the hot-bands are annealed at $600^{\circ} \mathrm{C}$ and $625^{\circ} \mathrm{C}$. So the poor $B_{8}$ results from the $\{211\}\langle 011\rangle$ secondary grains. The equiaxed secondary recrystallized grains have the $\{110\}\langle 001\rangle$ texture. When the hot-bands are annealed at $650^{\circ} \mathrm{C}$ and $675^{\circ} \mathrm{C}$, the secondary grains have the $\{110\}\langle 001\rangle$ texture.

\subsection{Microstructures and Textures of Hot-band An- nealed Specimens}

The optical micrographs after the hot-band annealing are given in Fig. 5. Deformed structure remains in the specimen after the hot-band annealing at $600^{\circ} \mathrm{C}$. This microstructure is mostly the same as that of the hot-band. Only the near surface layer and not the center layer recrystallize in the specimen after the hot-band annealing at $650^{\circ} \mathrm{C}$. All layers recrystallize in the specimen after hotband annealing at $700^{\circ} \mathrm{C}$ and coarser grains form at the center layer as compared with the surface layer.

The $\{100\}$ pole figures at the $1 / 10$ and $1 / 2$ thickness of the hot-band annealed specimens are given in Fig. 6. There is much amount of the $\{110\}\langle 001\rangle$ orientation at the $1 / 10$ thickness in all hot-band annealing conditions. There is much amount of $\alpha$-fiber (namely $\{100\}\langle 011\rangle$, $\{311\}\langle 011\rangle,\{211\}\langle 011\rangle$ and $\{111\}\langle 011\rangle)$ and $\gamma$-fiber (namely $\{111\}\langle u v w\rangle$ ) orientations at the $1 / 2$ thickness in all hot-band annealing conditions. Much amount of the $\{100\}\langle 011\rangle$ orientation at the $1 / 2$ thickness after hot-band annealing remains even the annealing temperature of $700^{\circ} \mathrm{C}$.

\subsection{Microstructures of Primary Recrystallized Spec- imens}

The optical micrographs after the primary recrystalliza-
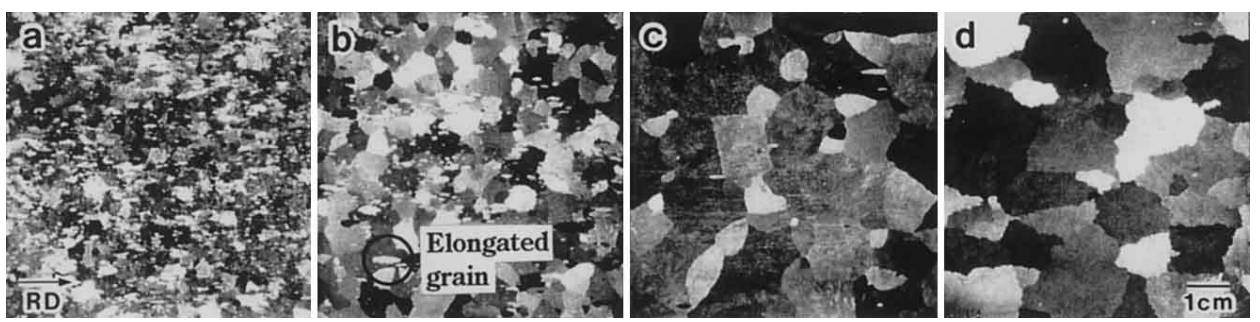

Fig. 3. Effect of hot-band annealing temperature on the macrostructures of secondary recrystallized grains. $\begin{array}{llll}\text { (a) } 600^{\circ} \mathrm{C} & \text { (b) } 625^{\circ} \mathrm{C} & \text { (c) } 650^{\circ} \mathrm{C} & \text { (d) } 675^{\circ} \mathrm{C}\end{array}$ 
tion annealing are given in Fig. 7. Effect of the hot-band annealing temperature on the average grain size is shown in Fig. 8. The average grain size increases with increasing the hot-band annealing temperature. So the average grain size is small at the hot-band annealing temperature of $600^{\circ} \mathrm{C}$. There is little difference between the two average primary recrystallized grain sizes when the hot-bands are annealed at $625^{\circ} \mathrm{C}$ and $650^{\circ} \mathrm{C}$ by chance. The grain size at the $1 / 2$ thickness is small but the grain size at the $1 / 10$ thickness is large at the hot-band annealing temperature of $650^{\circ} \mathrm{C}$. The grain size at the $1 / 2$ thickness is larger than that at the $1 / 10$ thickness at the hot-band annealing temperature of $700^{\circ} \mathrm{C}$.

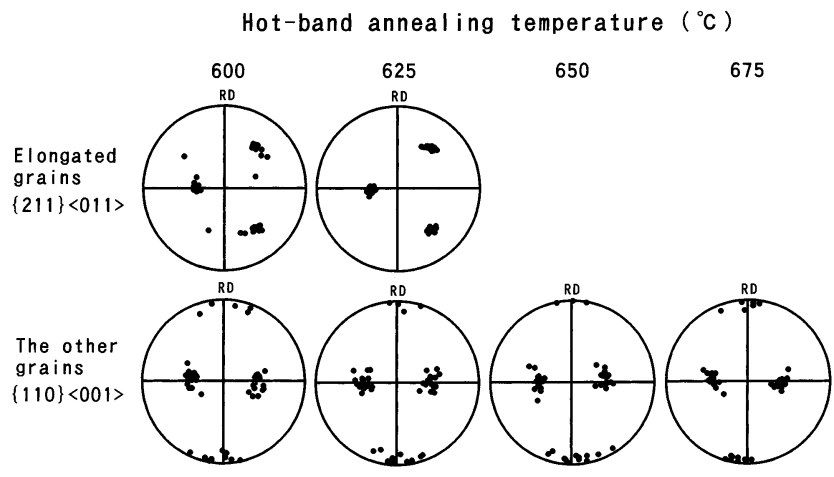

Fig. 4. Effect of hot-band annealing temperature on the $\{100\}$ pole figures of secondary recrystallized grains.
The grain structure after the primary recrystallization corresponds to that after the hot-band annealing: coarse grain structure after the hot-band annealing leads to coarse grain structure after the primary recrystallization; samely fine grain structure after the hot-band annealing also leads to fine grain structure after the primary recrystallization.

Figure 9 shows effect of the hot-band annealing temperature on the grain size distribution along the thickness direction. Hot-band annealing at $650^{\circ} \mathrm{C}$ and $675^{\circ} \mathrm{C}$ results in coarse grain structure near the surface layer. Hot-band an-

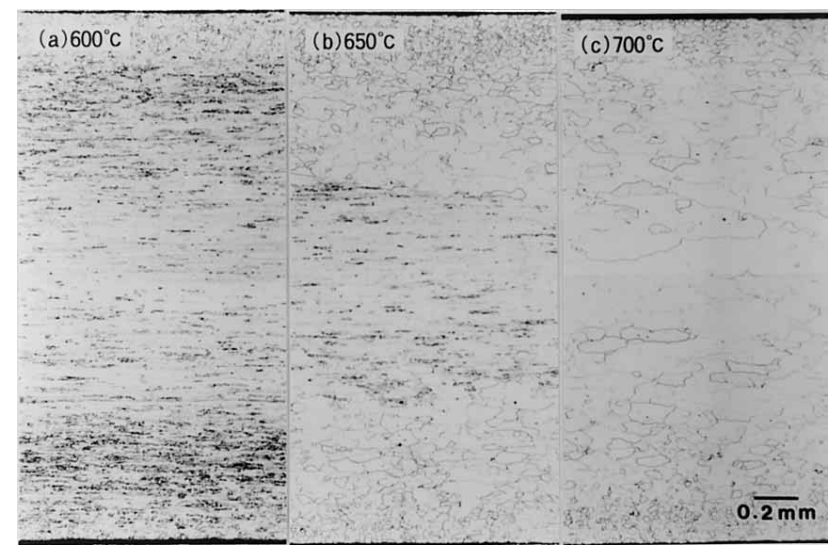

Fig. 5. Effect of hot-band annealing temperature on the microstructure after the hot-band annealing. $\begin{array}{lll}\text { (a) } 600^{\circ} \mathrm{C} & \text { (b) } 650^{\circ} \mathrm{C} & \text { (c) } 700^{\circ} \mathrm{C}\end{array}$
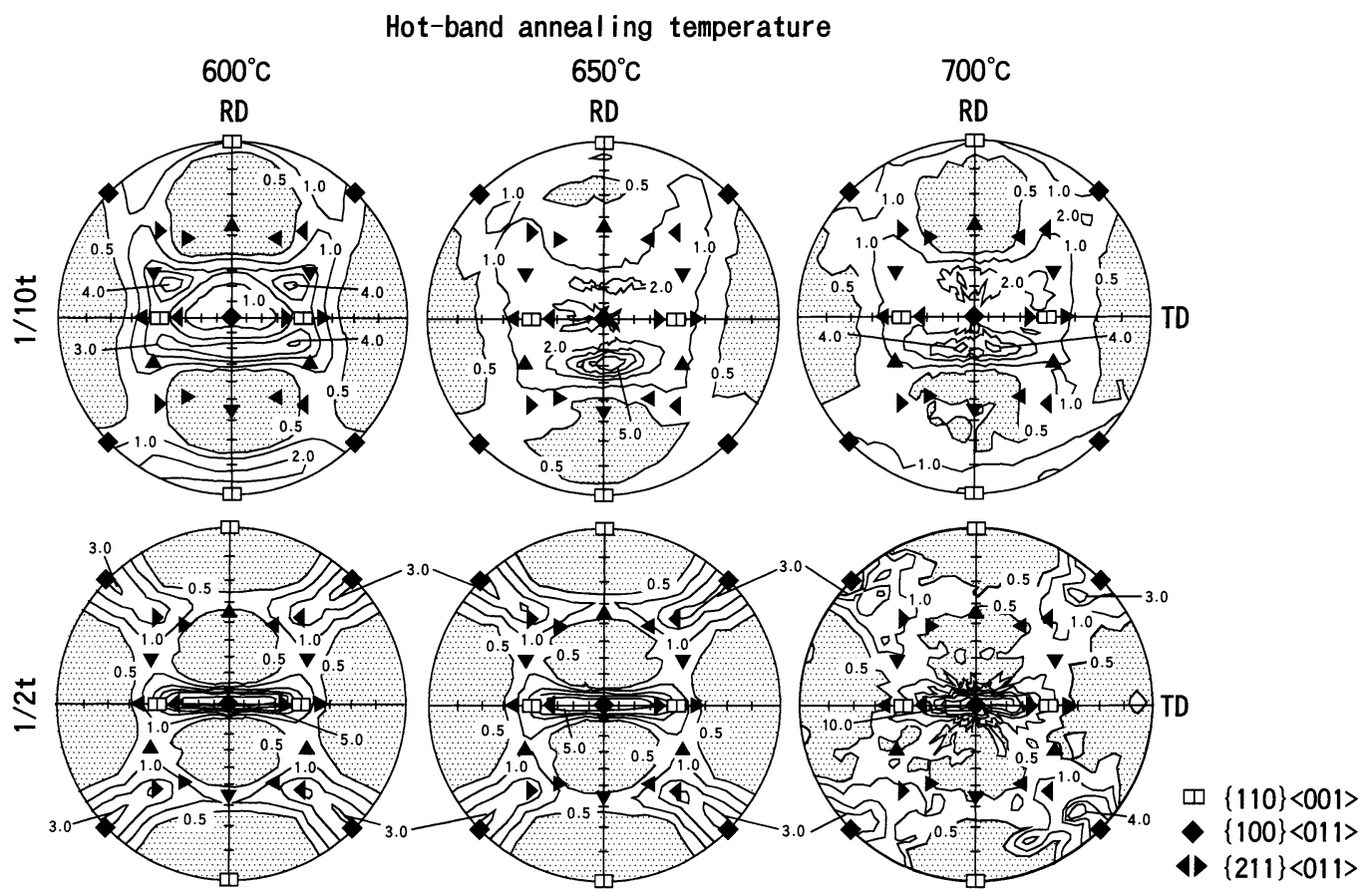

Fig. 6. Effect of hot-band annealing temperature on the $\{100\}$ pole figure at the $1 / 10$ and $1 / 2$ thickness of the $1 / 10$ and $1 / 2$ thickness of the specimens after the hot-band annealing.

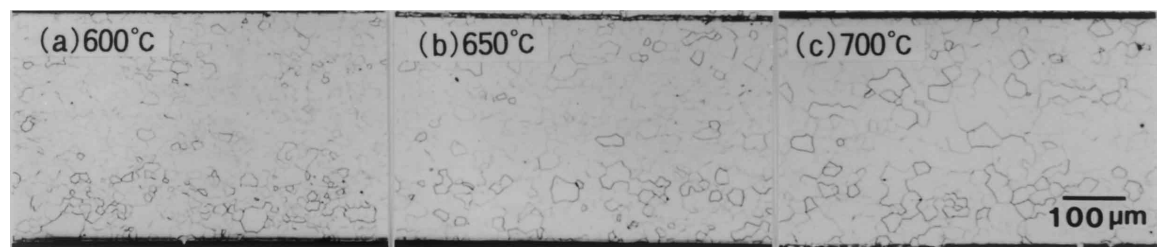

Fig. 7. Effect of hot-band annealing temperature on the microstructure after the primary recrystallization annealing. $\begin{array}{lll}\text { (a) } 600^{\circ} \mathrm{C} & \text { (b) } 650^{\circ} \mathrm{C} & \text { (c) } 700^{\circ} \mathrm{C} \text {. }\end{array}$ 
nealing at $700^{\circ} \mathrm{C}$ results in very coarse grain structure at the center layer. Also in the hot-band annealing temperature of $675^{\circ} \mathrm{C}$, coarse grains form partly at the center layer.

\subsection{Textures of Primary Recrystallized Specimens}

The $\{100\}$ pole figures at the $1 / 10$ and $1 / 2$ thickness of the primary recrystallized specimens are given in Fig. 10. There is little $\{110\}\langle 001\rangle$ component at the $1 / 10$ thickness when the hot-band is annealed at $600^{\circ} \mathrm{C}$. The $\{110\}\langle 001\rangle$ component forms at the $1 / 10$ thickness when the hot-bands are annealed at $650^{\circ} \mathrm{C}$ and $700^{\circ} \mathrm{C}$. On the other hand, there is mainly the $\{111\}\langle 112\rangle$ component at the $1 / 2$ thickness in all hot-band annealing conditions. Especially the $\{111\}\langle 112\rangle$ component is strong when the hot-bands are annealed at $600^{\circ} \mathrm{C}$ and $650^{\circ} \mathrm{C}$. But the $\{111\}\langle 112\rangle$ component decreases and the $\{110\}\langle 001\rangle$ component increases at the $1 / 2$ thickness when the hot-band is annealed at $700^{\circ} \mathrm{C}$.

Effect of the hot-band annealing temperature on the primary recrystallization texture, which indicates the $\{110\}\langle 001\rangle$, the $\{211\}\langle 011\rangle$ and the $\{111\}\langle 112\rangle$ orientation density at the $1 / 10$ and $1 / 2$ thickness is given in Fig. 11. The $\{110\}\langle 001\rangle$ density at the $1 / 10$ and $1 / 2$ thickness increases gradually with increasing the hot-band annealing

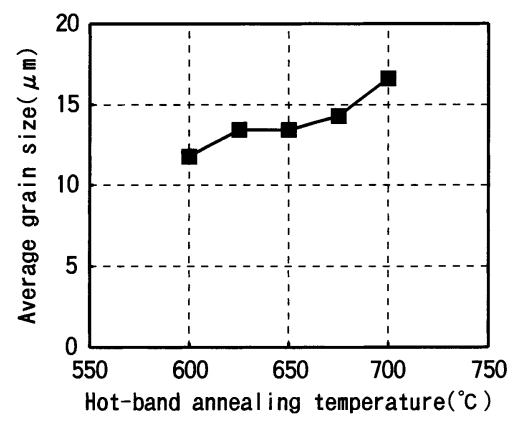

Fig. 8. Effect of hot-band annealing temperature on the average primary recrystallized grain size. temperature. Especially the $\{110\}\langle 001\rangle$ density at the $1 / 10$ in the condition of $650^{\circ} \mathrm{C}$ to $700^{\circ} \mathrm{C}$ is higher than that of 600 and $625^{\circ} \mathrm{C}$. On the other hand, the $\{110\}\langle 001\rangle$ density at the $1 / 2$ thickness is very low at the hot-band annealing temperature of not higher than $650{ }^{\circ} \mathrm{C}$ but suddenly increases very much at the hot-band annealing temperature of $675^{\circ} \mathrm{C}$. So the $\{111\}\langle 112\rangle$ orientation density at the $1 / 2$ thickness decreases very much at the same temperature. The $\{111\}\langle 112\rangle$ density at the $1 / 10$ thickness also decreases with increasing the hot-band annealing temperature. The $\{211\}\langle 011\rangle$ orientation density at the $1 / 10$ thickness is higher than that at the $1 / 2$ thickness.
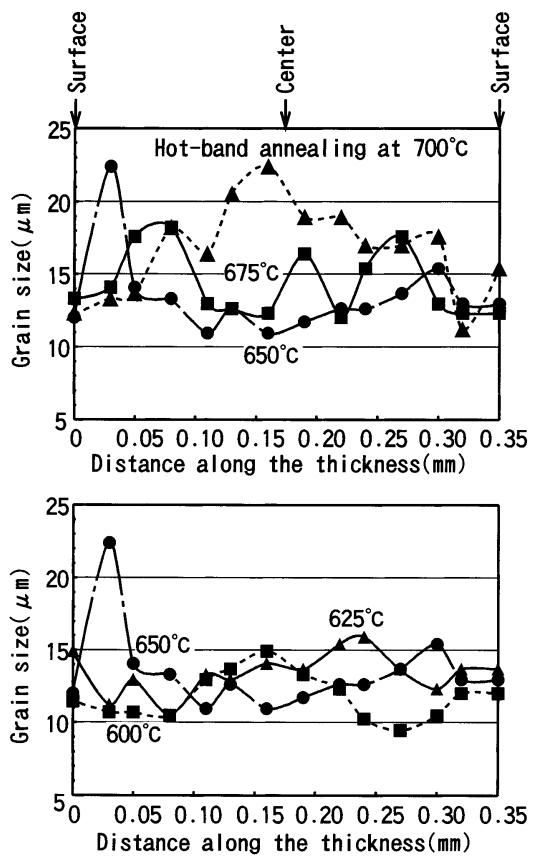

Fig. 9. Effect of the hot-band annealing temperature on the grain size distribution along the thickness.
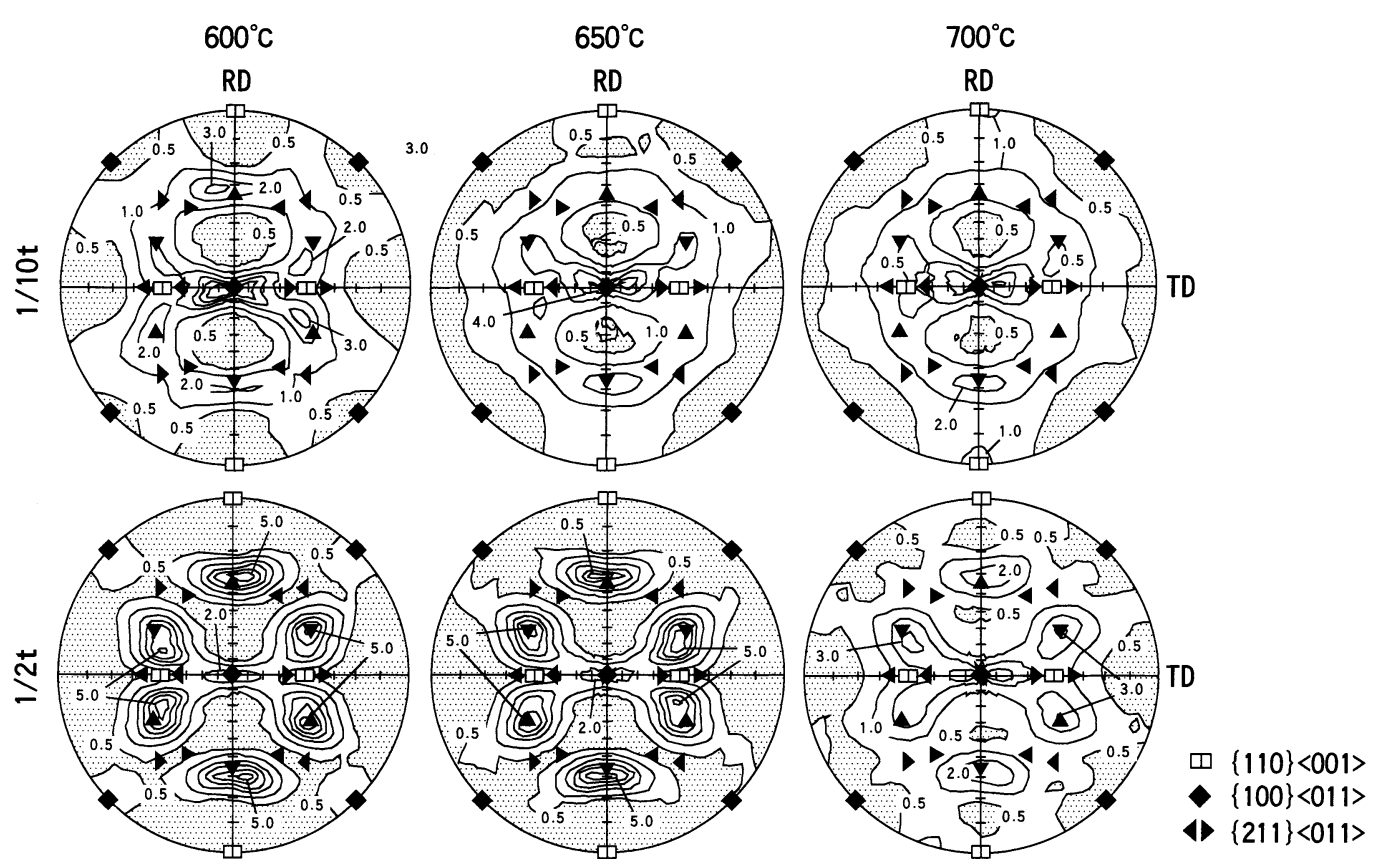

Fig. 10. Effect of hot-band annealing temperature on the $\{100\}$ pole figure at the $1 / 10$ and the $1 / 2$ thickness of the specimens after the primary recrystallization annealing. 


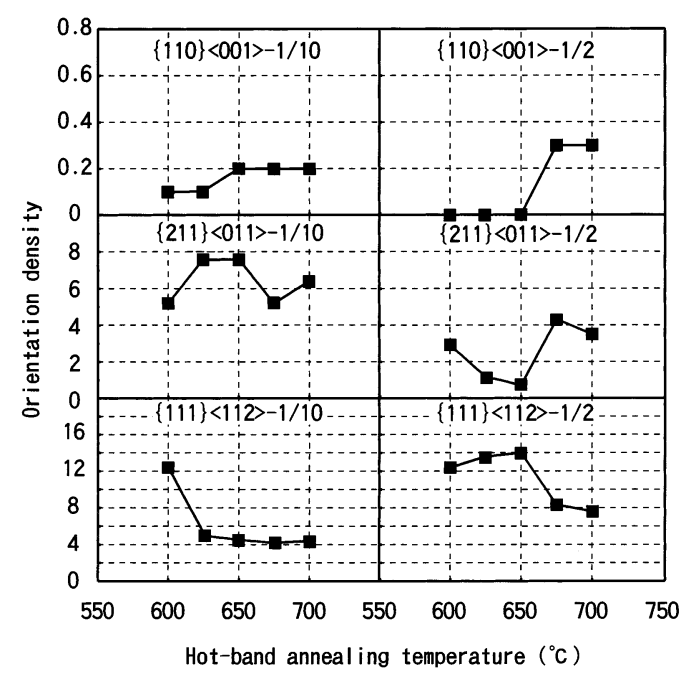

Fig. 11. Effect of hot-band annealing temperature on the $\{110\}\langle 001\rangle$, the $\{211\}\langle 011\rangle$ and the $\{111\}\langle 112\rangle$ orientation densities after the primary recrystallization annealing.

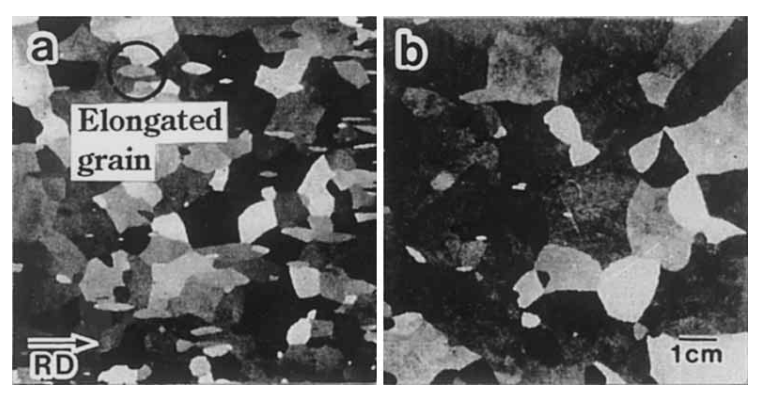

Fig. 12. Effect of $\mathrm{N}_{2}$ percentage in the annealing atmosphere on the microstructure after the secondary recrystallization annealing. The hot-bands were annealed at $650^{\circ} \mathrm{C}$. $\begin{array}{ll}\text { (a) } 5 \% \mathrm{~N}_{2}+95 \% \mathrm{~N}_{2} & \text { (b) } 15 \% \mathrm{~N}_{2}+95 \% \mathrm{H}_{2}\end{array}$

There seems small difference in the primary recrystallization texture between the two specimens hot-band annealed at $625^{\circ} \mathrm{C}$ and $650^{\circ} \mathrm{C}$. There is little difference in the $\{211\}\langle 011\rangle$ and the $\{111\}\langle 112\rangle$ orientation density between the two specimens. On the other hand, the $\{110\}\langle 001\rangle$ orientation density at both of the $1 / 10$ and $1 / 2$ thickness is weaker when the hot-band is annealed at $625^{\circ} \mathrm{C}$, compared with $650^{\circ} \mathrm{C}$.

\subsection{Effect of the Atmosphere in the Final Annealing on Secondary Recrystallization}

The specimens, hot-band-annealed at $650^{\circ} \mathrm{C}$, cold-rolled and primary-recrystallized, are secondary-recrystallized in two atmospheres of $15 \% \mathrm{~N}_{2}+85 \% \mathrm{H}_{2}$ and $5 \% \mathrm{~N}_{2}+95 \% \mathrm{H}_{2}$. Those macrostructures are given in Fig. 12. Decrease in $\mathrm{N}_{2}$ volume percentages from $15 \%$ to $5 \%$ in the atmosphere of the secondary recrystallization annealing results in smaller $\{110\}\langle 001\rangle$ oriented secondary grains and many elongated $\{211\}\langle 011\rangle$ oriented secondary grains. The $\{100\}$ pole figures of the secondary recrystallized grains are given in Fig. 13. Decrease in $\mathrm{N}_{2}$ volume percentage results in rough $\{110\}\langle 001\rangle$ oriented texture. Such phenomenon is considered to result from weaker inhibitor in the secondary recrystallization stage due to the decrease in the volume fraction of nitrides.

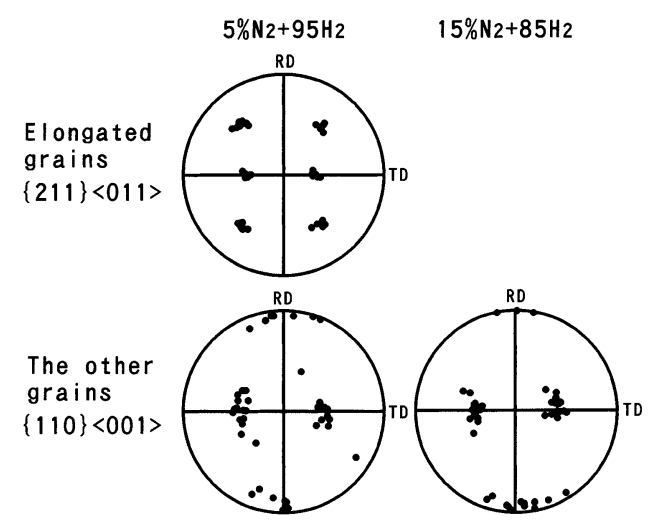

Fig. 13. Effect of $\mathrm{N}_{2}$ percentage in the annealing atmosphere on the $\{100\}$ pole figures of the secondary recrystallized grains.

\section{Discussion}

4.1. Mechanism of the $\{110\}\langle 011\rangle$ and the $\{111\}\langle 112\rangle$ Component Formation in the Primary Recrystallization Stage

Higher strain energy at the surface layer of the hot-band should accumulate than that at the center layer because of the friction with the rolls during the hot-rolling. So the surface layer of the hot-band recrystallizes earlier than the center layer during hot-band annealing. Thus heterogeneous microstructure along the thickness direction, as shown in Fig. 5, is easy to form after the hot-band annealing.

It has reported so far that cold-rolling and annealing of a $\{110\}\langle 001\rangle$ oriented single grain results in the $\{110\}\langle 001\rangle$ primary recrystallized component. ${ }^{4)}$ There is much amount of the $\{110\}\langle 001\rangle$ orientation at the $1 / 10$ thickness after the hot-band annealing in all conditions. However there are few $\{110\}\langle 001\rangle$ oriented grains at the $1 / 10$ thickness after the primary recrystallization when the hot-bands are annealed at $600^{\circ} \mathrm{C}$ and $625^{\circ} \mathrm{C}$. This is because there is fine grain structure at the $1 / 10$ thickness after the hot-band annealing. On the other hand, the $\{110\}\langle 001\rangle$ component in the primary texture is very high at the $1 / 2$ thickness when the hotbands are annealed at $675^{\circ} \mathrm{C}$ and $700^{\circ} \mathrm{C}$ although there is little $\{110\}\langle 001\rangle$ component at the $1 / 2$ thickness after the hot-band annealing. The reason is because there is coarse grain structure at the $1 / 2$ thickness after the hot-band annealing. So it is thought that the $\{110\}\langle 001\rangle$ component after the primary recrystallization annealing results from cold-rolling of the coarse grains.

Much amount of the $\{111\}\langle 112\rangle$ orientation is also necessary in the primary matrix texture for secondary recrystallization. $^{5)}$ This is because the $\{111\}\langle 112\rangle$ orientation has the relation of the rotation of $35^{\circ}$ with the $\{110\}\langle 001\rangle$ orientation around the common $\langle 110\rangle$ axis parallel to the transverse direction, given in Fig. 14(a). Such those boundaries are easy to move. $\left.{ }^{6}\right)$ The $\{111\}\langle 112\rangle$ orientation is easy to form when the fine grains structure is coldrolled and primary recrystallized. ${ }^{7}$ So much amount of the $\{111\}\langle 112\rangle$ orientation forms at the $1 / 2$ thickness after the primary recrystallization when the hot-bands are annealed at not higher than $650^{\circ} \mathrm{C}$. It decreases when the hot-bands were annealed at higher than $650^{\circ} \mathrm{C}$. The reason is because after the hot-band annealing at $700^{\circ} \mathrm{C}$, the coarse grains 
grow at the 1/2 thickness, given in Figs. 5 and 6.

Thus the experiment gives evidence that texture after the primary and secondary recrystallization behavior in the present process depends on the heterogeneous grain structure along the thickness direction rather than texture after the

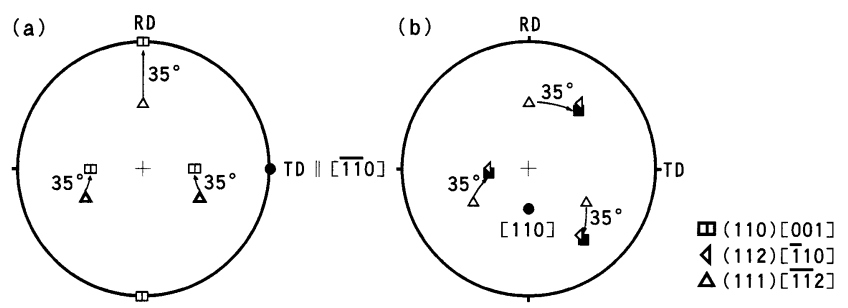

Fig. 14. $\{100\}$ pole figures showing the orientation relation of rotation of $35^{\circ}$ around the common $\langle 110\rangle$ axis from the (111) [1 $\overline{1} 2]$ orientation.

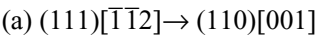

(b) (111) $[\overline{1} \overline{1} 2] \rightarrow \sim(112)[\overline{1} 10]$ hot-band annealing.

The texture formation mechanism is summarized in Fig. 15.

In the hot-band annealing condition of 600 and $625^{\circ} \mathrm{C}$, as the parent materials for cold-rolling consist of fine and deformed grains, the primary recrystallized textures consist of much $\{111\}\langle 112\rangle$ and $\{211\}\langle 011\rangle$ component and little $\{110\}\langle 001\rangle$ component.

In the hot-band annealing condition of $650^{\circ} \mathrm{C}$, the parent materials for cold-rolling consists of coarse grains at the surface and deformed fine grains at the center layer. So the primary recrystallization textures consist of a little $\{110\}\langle 001\rangle$ and much $\{211\}\langle 011\rangle$ components at the surface layer and much $\{111\}\langle 112\rangle$ component at the center layer.

In the hot-band annealing condition of $675^{\circ} \mathrm{C}$, the parent material for cold-rolling has the nearly same structure as that in the condition of $650^{\circ} \mathrm{C}$. But as there are also some coarse grains at the center layer after the hot-band anneal-

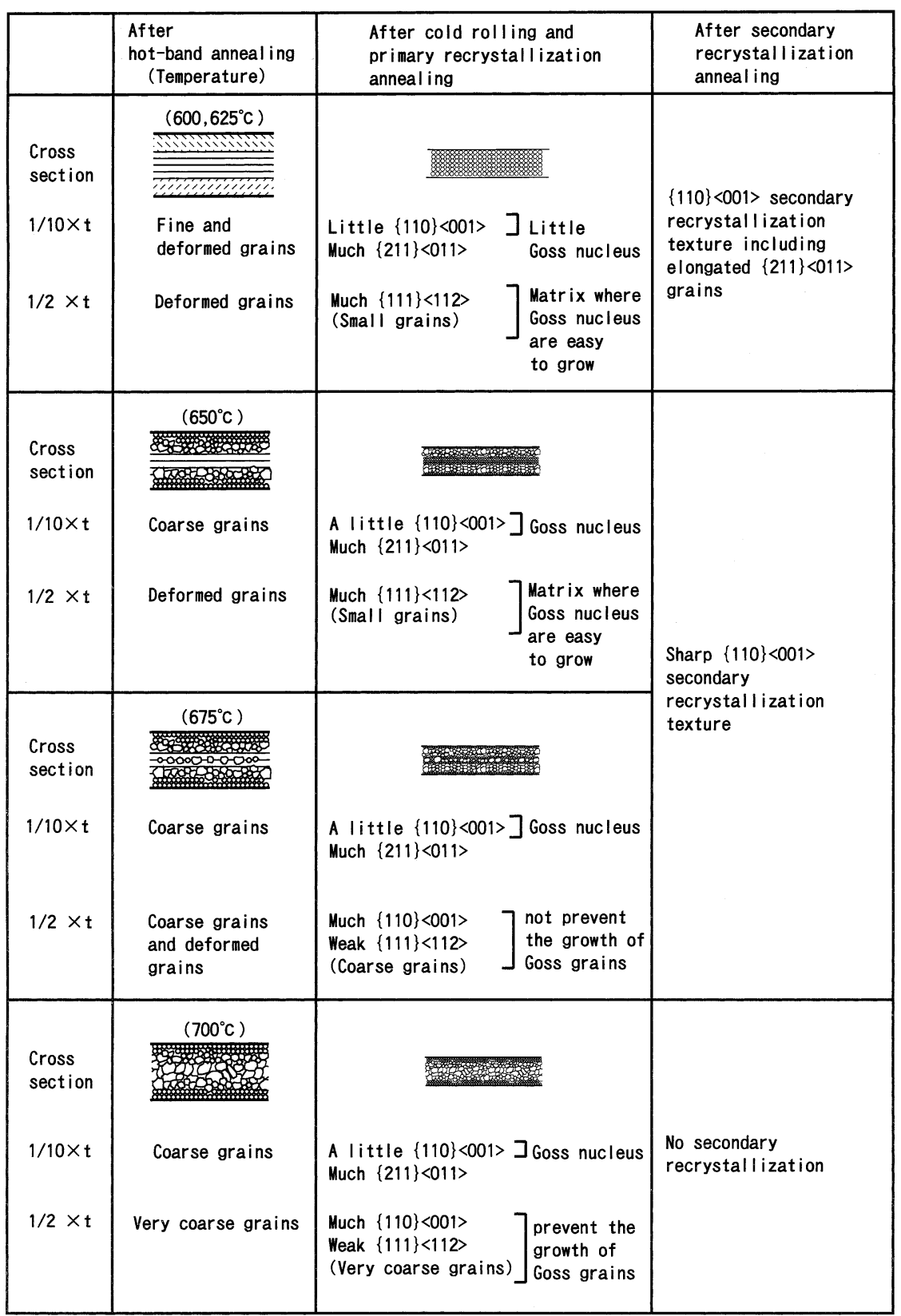

Fig. 15. Summary of the change in the texture and the microstructures. 
ing, the primary recrystallization texture includes much $\{110\}\langle 001\rangle$ component at the center layer.

In the hot-band annealing condition of $700^{\circ} \mathrm{C}$, the parent materials for cold-rolling consists of coarse grains at the surface layer and very coarse grains at the center layer. So the primary recrystallization texture consists of a little $\{110\}\langle 001\rangle$ and much $\{211\}\langle 011\rangle$ component at the surface layer and much $\{110\}\langle 001\rangle$ and weak $\{111\}\langle 112\rangle$ component at the center layer.

\subsection{Mechanism of Secondary Recrystallization of the $\{110\}\langle 001\rangle$ and the $\{211\}\langle 011\rangle$ Orientation}

It has been said conventionally that the grain boundaries having a special orientation relation migrate more rapidly than the general grain boundaries. ${ }^{6}$ The $\{100\}$ pole figures representing the orientation rotation relation are given in Fig 14. There is the relation of $35^{\circ}$ rotation around the $\langle 110\rangle$ axis parallel to the transverse direction between the $\{110\}\langle 001\rangle$ orientation and the $\{111\}\langle 112\rangle$ orientation. However, there is also very near relation between the $\{211\}\langle 011\rangle$ orientation and the $\{111\}\langle 112\rangle$ orientation, shown in Fig. 14(b). So the $\{211\}\langle 011\rangle$ oriented grains are easy to grow in the matrix of the $\{111\}\langle 112\rangle$ orientation as the main component of the texture. This can be considered the reason why the secondary recrystallization of the $\{211\}\langle 011\rangle$ orientation occurs.

Many elongated $\{211\}\langle 011\rangle$ oriented secondary grains form when the hot-bands were annealed at 600 and $625^{\circ} \mathrm{C}$, compared with $650^{\circ} \mathrm{C}$. There is little difference between the two average primary recrystallized grain sizes when the hot-bands were annealed at $625^{\circ} \mathrm{C}$ and $650^{\circ} \mathrm{C}$. There is little difference in the $\{211\}\langle 011\rangle$ and the $\{111\}\langle 112\rangle$ orientation density between the two specimens. On the other hand, the $\{110\}\langle 001\rangle$ orientation density at both of the $1 / 10$ and $1 / 2$ thickness is very weak when the hot-band was annealed at $625^{\circ} \mathrm{C}$, compared with $650^{\circ} \mathrm{C}$. The inhibitor intensity is fixed because nitrides as the inhibitor form in the heating stage of final annealing. So it is concluded that the $\{110\}\langle 001\rangle$ secondary grains mixed with many $\{211\}\langle 011\rangle$ secondary grains form when the $\{110\}\langle 001\rangle$ orientation density is too weak in the primary recrystallization texture in the case of the same inhibitor intensity.

The $\{110\}\langle 001\rangle$ component forms at the $1 / 10$ thickness after the primary recrystallization when the coarse grain zone forms at the 1/10 thickness after the hot-band annealing at not lower than $650^{\circ} \mathrm{C}$. So the secondary recrystallization of the $\{110\}\langle 001\rangle$ orientation can occur in these conditions since there is adequate amount of Goss nucleus.

But although the $\{211\}\langle 011\rangle$ orientation density is much higher than the $\{110\}\langle 001\rangle$ orientation density in the primary recrystallization texture, the secondary recrystallization of the $\{110\}\langle 001\rangle$ orientation occurs preferentially, compared with that of the $\{211\}\langle 011\rangle$ orientation when the hot-band was annealed at $650^{\circ} \mathrm{C}$. The fact suggests that the orientation rotation relation cannot accommodate preferential secondary recrystallization of the $\{110\}\langle 001\rangle$ orientation.

\subsection{Mechanism of no Secondary Recrystallization}

The $\{111\}\langle 112\rangle$ orientation density is weak at the $1 / 2$ thickness when the hot-bands are annealed at 675 and $700^{\circ} \mathrm{C}$. So there are small amount of high angle boundaries in these conditions and Goss nucleus are difficult to grow from the viewpoint of only texture. But secondary recrystallization behavior are very different between these two conditions. It may be attributable to different primary recrystallized grain structures between these two conditions. It is thought that very coarse primary grains at the center layer prevent secondary recrystallization in the hot-band annealing condition of $700^{\circ} \mathrm{C}$. On the other hand, the amount of coarse primary grains in the condition of $675^{\circ} \mathrm{C}$ is less than that in the condition of $700^{\circ} \mathrm{C}$. In addition, such phenomena can occur as secondary recrystallized grains form on a surface of a sheet and no secondary recrystallized grains form on the opposite surface of the sheet in the condition of $700^{\circ} \mathrm{C}$. So very coarse primary grains at the center layer can be the reason why no secondary recrystallization occur and the $B_{8}$ indicates a low value in this conditions.

Thus amount of $\{110\}\langle 001\rangle$ component, grain size structure in the primary recrystallized stage and inhibitor intensity should be satisfied for development of sharp $\{110\}\langle 001\rangle$ texture.

\section{Conclusion}

(1) Secondary recrystallization behavior in final annealing is strongly affected by the hot-band annealing condition. Namely it is considered to depend on the heterogeneous grain structure along the thickness direction after the hot-band annealing.

(2) When the hot-bands didn't recrystallize after the hot-band annealing at 600 and $625^{\circ} \mathrm{C}$, secondary recrystallization of the $\{110\}\langle 001\rangle$ orientation mixed with the $\{211\}\langle 011\rangle$ orientation forms. So magnetic induction $B_{8}$ indicates very low value. The reason is because the $\{110\}\langle 001\rangle$ orientation density is too weak in the primary recrystallization texture. That also occurs when the inhibitor is also too weak in the secondary recrystallization stage.

(3) Fully recrystallized hot-band after annealing at $700^{\circ} \mathrm{C}$ leads to no secondary recrystallization and lower $B_{8}$ value. This is because very coarse primary recrystallized grains at the center layer prevent secondary recrystallization.

(4) Secondary recrystallization of the $\{110\}\langle 001\rangle$ orientation evolves completely and the magnetic induction $\mathrm{B}_{8}$ indicates the highest value when only near surface layer but not the center layer of the hot-band recrystallizes after the hot-band annealing at 650 and $675^{\circ} \mathrm{C}$. The reason is that amount of $\{110\}\langle 001\rangle$ component in the primary texture, the inhibitor intensity and the primary matrix grain size structure are satisfied.

\section{REFERENCES}

1) H. Yashiki and T. Kaneko: J. Appl. Phys., 73 (1993), 6606.

2) S. Taguchi, A. Sakakura and H. Takashima: U.S. Patent 3287183 (1966).

3) S. Nagashima: J. Jpn. Inst. Met., 21 (1982), 842.

4) J. L. Walter and W. R.Hibbard: Trans. AIME, 212 (1958), 731.

5) J. Harase and R. Shimizu: J. Jpn. Inst. Met., 54 (1990), 1.

6) E. Furubayashi: Trans. Iron Steel Inst. Jpn., 9 (1969), 222.

7) H. Inagaki, Tetsu-to-Hagané, 62 (1976), 1000. 